\title{
Expression of glucocorticoid receptor, mineralocorticoid receptor, and $11 \beta$-hydroxysteroid dehydrogenase 1 and 2 in the fetal and postnatal ovine hippocampus: ontogeny and effects of prenatal glucocorticoid exposure
}

\author{
Deborah M Sloboda ${ }^{1,2}$, Timothy J M Moss ${ }^{1,2}$, Shaofu $\mathrm{Li}^{1}$, Stephen G Matthews ${ }^{4}$, John R G Challis ${ }^{3,4}$ \\ and John P Newnham ${ }^{1,2}$ \\ ${ }^{1}$ School of Women's and Infants' Health, The University of Western Australia, Perth 6009, Australia \\ ${ }^{2}$ Women and Infants Research Foundation, Perth 6009, Australia \\ ${ }^{3} \mathrm{CIHR}$ Group in Fetal and Neonatal Health and Development and ${ }^{4}$ Departments of Physiology and Obstetrics and Gynecology, University of Toronto, Toronto, \\ Ontario, M5S1 AB Canada \\ (Correspondence should be addressed to D M Sloboda who is now at The Liggins Institute, Auckland Mail Centre, The University of Auckland, 2-6 Park Avenue, \\ Grafton, Auckland, Private Bag 92019, Auckland 1142, New Zealand; Email: d.sloboda@auckland.ac.nz)
}

\begin{abstract}
To determine the expression of glucocorticoid metabolizing and action genes in the hippocampus of fetal, neonatal, and adult sheep. Pregnant ewes (or their fetuses) received intramuscular injections of saline or betamethasone (BETA, $0-5 \mathrm{mg} / \mathrm{kg}$ ) at 104, 111, 118, and/or 125 days of gestation (dG). Hippocampal tissue was collected prior to $(75,84$, and $101 \mathrm{dG})$, during (109 and 116 $\mathrm{dG})$, or after $(121,132$, and $146 \mathrm{dG} ; 6$ and 12 postnatal weeks; $3 \cdot 5$ years of age) saline or BETA injections. Hippocampal glucocorticoid receptor (GR), mineralocorticoid receptor (MR), and

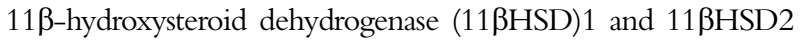
mRNA levels were determined using qRT-PCR. Control animals late in gestation demonstrated a decrease in mRNA encoding GR and $11 \beta \mathrm{HSD} 1$, whereas $11 \beta \mathrm{HSD} 2$ was undetectable, consistent with a damping of the negative feedback influence of circulating or locally produced cortisol on the hypothalamic-pituitary-adrenal
\end{abstract}

(HPA) axis. BETA-administration had transient effects on fetal GR and MR, and early in postnatal life (12 weeks of age) $11 \beta \mathrm{HSD} 1 \mathrm{mRNA}$ was increased. Hippocampal MR mRNA was elevated in adult offspring exposed to either one or four doses of maternal BETA $(P<0 \cdot 001)$. Four courses of maternal BETA increased $11 \beta \mathrm{HSD} 2(P<0 \cdot 05)$ but not $11 \beta \mathrm{HSD} 1$ mRNA levels. Late in gestation a reduction in hippocampal GR and 11ßHSD1 mRNA suggests lessening of glucocorticoid negative feedback, facilitating increased preterm HPA activity and parturition. Adult offspring of BETA-treated mothers demonstrated increased MR and 11ßHSD2 mRNA, therefore it appears that exposure of fetus to high levels of synthetic glucocorticoids may have long-lasting effects on the hippocampal expression of HPA-related genes into adulthood.

Journal of Endocrinology (2008) 197, 213-220

\section{Introduction}

A late gestational rise in endogenous plasma cortisol levels occurs in the fetuses of many species and is necessary for tissue and organ maturation as well as for the initiation of parturition (Liggins 1994). This trend corresponds to a widely observed increase in hypothalamic-pituitary-adrenal (HPA) activity in late gestation, but presumably also requires a lessening of negative regulatory control of HPA activity. We have previously reported changes in gene expression in the fetal ovine hypothalamus and pituitary consistent with a late gestational maturation of these organs (Matthews \& Challis 1996), but there is limited information on hippocampal gene expression ontogeny in the context of changes in negative regulatory control of HPA activity in late gestation in the fetal sheep (Keller-Wood et al. 2006). Hippocampal corticosteroid receptors (both type 1 (mineralocorticoid receptor, MR) and type 2 (glucocorticoid receptor, GR)) and metabolizing enzymes (11 $\beta$-hydroxysteroid dehydrogenases, $11 \beta \mathrm{HSD}$ ) regulate glucocorticoid action, but their role in fetal HPA axis activation is unclear. It is possible that interaction between these regulators plays a role in the well-known attenuation of negative feedback occurring late in gestation (Matthews \& Challis 1996) and facilitates the rise in bioactive cortisol levels necessary for the maturation of fetal organ systems.

While elevated cortisol levels during late pregnancy are required for normal fetal development (Liggins 1994), we have previously shown that inappropriate exposure to endogenous or exogenous glucocorticoids results in a number of adverse outcomes for the fetus, including fetal growth restriction (Newnham et al. 1999), reduced brain growth (Huang et al. 1999), reduced neuronal myelination (Quinlivan et al. 1999), and fetal HPA hyperactivity near term (Sloboda et al. 2000). Studies by 
others have shown that early developmental influences affecting HPA axis function may have profound long-term programming changes at the level of the hippocampus (Meaney \& Aitken 1985, Meaney et al. 1989, Levitt et al. 1996).

In the present study, we investigated changes in the expression of four key hippocampal genes in the prenatal sheep, in order to elucidate the contribution of the hippocampus to negative regulatory control of HPA activity during late gestation and early postnatal life. We also examined the effects of exogenous glucocorticoids given to the mother or the fetus on both pre-and post-partum hippocampal GR, MR, and 11ßHSD expression levels, in order to determine whether short- or long-term changes in hippocampal gene expression result from exposure to inappropriate levels of glucocorticoids during pregnancy.

\section{Materials and Methods}

Experimental procedures were approved by the Animal Experimentation Ethics Committee of the University of Western Australia and/or the Western Australian Department of Agriculture.

\section{Prenatal and postnatal procedures}

Prenatal interventions, pregnancy outcomes, and postnatal care of animals have been described in detail previously (Sloboda et al. 2000, Moss et al. 2001). All animals (control and treatment groups) were injected intramuscularly with $150 \mathrm{mg}$ medroxyprogesterone acetate (Depo Provera; Upjohn, Rydalmere, Australia) at 100 $\mathrm{dG}$ to reduce pregnancy losses due to subsequent glucocorticoid treatment (Nathanielsz et al. 1988, Jobe et al. 1998). This study involves the combination of two cohorts of animals: Cohort 1, a cohort designed to investigate the effects of maternal betamethasone injection on fetal development throughout gestation and early neonatal life; and Cohort 2, a cohort designed to evaluate long-term effects of prenatal maternal or fetal betamethasone injections on adult sheep offspring.

\section{Cohort 1 - fetal and early postnatal development} Pregnant Merino ewes bearing singleton male fetuses of known gestational age were randomized to receive maternal injections of saline or betamethasone. Pregnant animals received intramuscular injections of saline or one (104 dG), two $(104,111 \mathrm{dG})$, or three $(104,111$, and $118 \mathrm{dG})$ injections of betamethasone $(0.5 \mathrm{mg} / \mathrm{kg}$ ewe weight; Celestone Chronodose; Schering Plough, Baulkham Hills, Australia). Saline injections were of a comparable volume $(5-6 \mathrm{ml})$. Hippocampal tissue was collected prior to $(75,84$, and 101 $\mathrm{dG})$, during (109 and $116 \mathrm{dG}$ ), or after $(121,132$, and146 dG, and at 6 and 12 postnatal weeks of age) either saline or betamethasone injections (Table 1). For fetal tissue collection, pregnant ewes were killed with captive bolt and fetuses were delivered by Caesarean section, weighed, and killed by decapitation. For collection of tissue from neonatal lambs,
Table 1 Sample size at each gestational age in fetal and neonatal animals (Cohort 1)

\begin{tabular}{|c|c|c|}
\hline \multirow[b]{2}{*}{ Age } & Saline groups & Betamethasone groups \\
\hline & & \\
\hline $75 \mathrm{dG}$ & 9 & - \\
\hline $84 \mathrm{dG}$ & 7 & - \\
\hline $101 \mathrm{dG}$ & 8 & - \\
\hline $109 \mathrm{dG}$ & 6 & 6 \\
\hline $116 \mathrm{dG}$ & 6 & 6 \\
\hline $121 \mathrm{dG}$ & 6 & 4 \\
\hline $132 \mathrm{dG}$ & 5 & 4 \\
\hline $146 \mathrm{dG}$ & 5 & 3 \\
\hline 6 weeks & 6 & 6 \\
\hline 12 weeks & 6 & 4 \\
\hline
\end{tabular}

pregnant ewes were permitted to deliver spontaneously and lambs were kept with ewes until the time of killing. For tissue collection lambs were sedated with ketamine $(15 \mathrm{mg} / \mathrm{kg})$ and xylazine $(0.1 \mathrm{mg} / \mathrm{kg}$, Troy Laboratories, Smithfield, NSW, Australia) and then killed by decapitation.

Cohort 2 - postnatal adult offspring Pregnant Merino ewes bearing singleton fetuses were allocated randomly to receive either maternal or fetal intramuscular injections of saline and/or betamethasone $(0.5 \mathrm{mg} / \mathrm{kg})$. Saline-treated groups were injected with normal saline at 104, 111, 118, and $125 \mathrm{dG}$. Single betamethasone dose groups were injected at 104 days of gestation and saline at 111,118 , and 125 days of gestation. Repeated betamethasone dose groups were injected with betamethasone at 104, 111, 118, and 125 days of gestation. Fetal intramuscular injections of betamethasone were given under ultrasound guidance using an established technique (Newnham et al. 1999). We have previously published the results of in vivo HPA experimentation on these offspring at 6 months and 1 year of age (Sloboda et al. 2002), and at 2 and 3 years of age (Sloboda et al. 2007), as well as metabolic experimentation at 6 months and 1 year (Moss et al. 2001) and at 2 and 3 years old (Sloboda et al. 2005). At $\sim 3.5$ years of age all offspring were weighed and killed by pentobarbitone overdose (30 mg/kg, Valabarb, Jurox Pty Ltd, Silverwater, Australia).

Offspring were grouped according to prenatal treatments as follows: maternal saline, $\operatorname{MS}(n=5$, male $n=3$, female $n=2)$ or fetal saline, FS $(n=4$, male $n=1$, female $n=3)$; single maternal betamethasone, M1 $(n=5$, male $n=2$, female $n=3)$ or single fetal betamethasone, F1 ( $n=7$, male $n=4$, female $n=3)$; four maternal betamethasone injections, M4 $(n=5$, male $n=2$; female $n=3)$; four fetal betamethasone injections, F4 $(n=4$, male $n=2$; female $n=2$ ).

All hippocampal tissue samples were recovered immediately, snap frozen in liquid $\mathrm{N}_{2}$, and stored at $-80^{\circ} \mathrm{C}$ until required for RNA extraction and gene expression analyses.

\section{Molecular analyses}

RNA extraction and reverse transcription (RT) Total RNA was extracted using the RNeasy Midi kit 
(Qiagen Pty Ltd). Genomic DNA contamination was removed from each sample using a DNase treatment (Ambion, Austin, TX, USA). Briefly, samples were incubated in $10 \times$ DNase I buffer and recombinant DNase I (rDNase I) for 25 min at $37^{\circ} \mathrm{C}$. Samples were eluted through micro-columns and then incubated with DNase Inactivation Reagent, centrifuged at $10000 \mathrm{~g}$ and stored at $-80^{\circ} \mathrm{C}$. One microgram of total RNA was RT in a $10 \mu \mathrm{l}$ reaction containing: $5 \times$ Moloney Murine Leukemia Virus RT (M-MLV RT) reaction buffer, $10 \mathrm{mM}$ dNTP, $10 \mathrm{mM}$ random hexamers, and $200 \mathrm{U} / \mu \mathrm{M}-\mathrm{MLV}\left(\mathrm{H}^{-}\right)$ reverse transcriptase (Promega). The RT reactions were carried out in a Peltier Thermal Cycler (MJ Research, Ramsey, MN, USA) at $22^{\circ} \mathrm{C}$ for $10 \mathrm{~min}, 55^{\circ} \mathrm{C}$ for $50 \mathrm{~min}$, and $70^{\circ} \mathrm{C}$ for $15 \mathrm{~min}$. Each sample of cDNA was purified using the Qiagen PCR Purification Kit (Qiagen Pty Ltd) and stored at $-20^{\circ} \mathrm{C}$.

Quantitative real-time PCR assays For the quantification of hippocampal MR, GR, and 11ßHSD1 and 2, and of the endogenous reference $18 \mathrm{~S}$ ribosomal RNA (18S), a quantitative PCR assay was performed (Rotor-Gene 3000, Corbett Research, Sydney, Australia). For quantitative PCR all primers were either designed using Primer 3.0 (PE Biosystems; for 11ßHSD1 accession number 001009395) or have been previously used on ovine tissue (GR, MR, 11ßHSD2, 18S; Dodic et al. 2002, Sloboda et al. 2007). Primer sequences for hippocampal MR, GR, 11 BHSD1 and 2 and 18S sets are presented in Table 2. PCRs were carried out in $25 \mu$ volumes containing of $10 \times$ IMMUNO Buffer (Bioline, Randolph, MA, USA), $3 \mathrm{mM} \mathrm{MgCl}_{2}$ (Bioline), $10 \mathrm{mM}$ dNTPs (Roche), $0 \cdot 5 \mu \mathrm{M}$ forward primer, $0.5 \mu \mathrm{M}$ reverse primer, SYBR Green (1: 2000; Fisher Biotech, Perth, Australia), and $5 \mathrm{U} / \mu \mathrm{l}$ IMMOLASE DNA polymerase (Bioline).

For tissues collected from fetal and neonatal lambs (Cohort 1 ), complementary DNA was amplified using the following cycling conditions: $95^{\circ} \mathrm{C}$ for $0 \mathrm{~s}, 62^{\circ} \mathrm{C}$ for $15 \mathrm{~s}$, and $72{ }^{\circ} \mathrm{C}$ for $10 \mathrm{~s}$. Annealing temperatures varied according to the gene of interest: $62{ }^{\circ} \mathrm{C}$ for $18 \mathrm{~S} ; 59^{\circ} \mathrm{C}$ for MR and GR; and $60^{\circ} \mathrm{C}$ for $11 \beta$ HSD 1 . In fetal hippocampal samples amplification of $11 \beta \mathrm{HSD} 2$ product was only achievable after $>50$ cycles. It was therefore deemed that $11 \beta$ HSD 2 mRNA in these samples was beyond the level of detection. The threshold cycle number of detection for each sample was compared against a standard curve constructed using tenfold serial dilutions of corresponding standards specific for each transcript. GR, MR, 11ßHSD1, and 18S standards were constructed using serial dilutions of conventional PCR product as a template. All samples for each gene of interest were run in duplicate. Results were expressed as a ratio of transcript (gene of interest) to internal control (18S). Inter-assay coefficient of variation was $<10 \%$.

For tissues collected from adult sheep (Cohort 2), complementary DNA was amplified for all transcripts using the following cycling conditions: $95^{\circ} \mathrm{C}$ for $0 \mathrm{~s}, 59^{\circ} \mathrm{C}$ for $15 \mathrm{~s}$, and $72{ }^{\circ} \mathrm{C}$ for $10 \mathrm{~s}$, for 35 cycles. A comparative cycle of threshold fluorescence $\left(C_{\mathrm{T}}\right)$ method was used to assess relative gene expression levels, where the $C_{\mathrm{T}}$ value reflects the cycle number at which DNA amplification is first detected. Equal amplification efficiencies were confirmed between the gene of interest and the internal control 18S. One control sample within each assay for each gene was used as a calibrator. Thus comparative $C_{\mathrm{T}}$ calculations for the expression of hippocampal GR, MR, $11 \beta \mathrm{HSD} 1$, and 2 were all relative to a calibrator. First, $18 \mathrm{~S} C_{\mathrm{T}}$ values were subtracted from hippocampal GR, MR, 11 $\beta$ HSD1, and 2 mRNA values for each sample to give a $\Delta C_{\mathrm{T}}$ value. $\Delta \Delta C_{\mathrm{T}}$ values were achieved by subtracting the calibrator $\Delta C_{\mathrm{T}}$ value from each sample $\Delta C_{\mathrm{T}}$ value. The expression of hippocampal GR, MR, $11 \beta$ HSD1, and 2 relative to the calibrator was evaluated using the expression $2^{-\Delta \Delta C_{\mathrm{T}}}$. This method of analysis has been previously published using sheep RNA (Dodic et al. 2002, Sloboda et al. 2007). All samples for each gene of interest were run in duplicate in a single assay. Intra-assay coefficient of variation was $<5 \%$.

Melting curve analysis demonstrated a single PCR product for MR, GR, $11 \beta \mathrm{HSD} 1,11 \beta \mathrm{HSD} 2$, and $18 \mathrm{~S}$ in all the collected tissues, and the presence of a single band at the appropriate molecular weight was confirmed by gel electrophoresis (data not shown).

\section{Statistical analysis}

Data analysis was carried out using Sigma Stat statistical software. To determine changes in mRNA levels due to gestational and

Table 2 Primer sequences used in quantitative RT-PCR

Sequence $5^{\prime}-3^{\prime}$

\section{Gene}

Glucocorticoid receptor (Fwd) Glucocorticoid receptor (Rev) Mineralocorticoid receptor (Fwd) Mineralocorticoid receptor (Rev) $11 \beta \mathrm{HSD} 1$ (Fwd)

$11 \beta$ HSD1 (Rev)

$11 \beta \mathrm{HSD} 2$ (Fwd)

$11 \beta$ HSD2 (Rev)

Internal control 18S (Fwd)

Internal control 18S (Rev)

\author{
ACTGCCCCAAGTGAAAACAGA \\ GCCCAGTTTCTCCTGCTTAATTAC \\ TCCAAAGGATGGCCTCAAAA \\ ATCTTTCTCAGCTCCTTGATGTAATTT \\ ATCCCTGTCTGATGGCTTTT \\ TGGTCTGAATTCCTCATTCG \\ AGCAGGAGACATGCCCGTTTC \\ GCAATGCCAAGGCTGCTT \\ ATCGGGGATTGCAATTATTC \\ GTGTACAAAGGGCAGGGACT
}

\section{Product size (bp)}

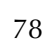

73

98

67

92 
early postnatal age, data from controls in Cohort 1 (75 dG to 12 weeks) were compared using one-factor analysis of variance, with age as the factor. To investigate the effect of betamethasone treatment in Cohort 1, data from tissues collected at 109, 116, 121, 132, and $146 \mathrm{dG}$ and at 6 and 12 weeks of age were compared using two-factor analysis of variance with gestational age and treatment as factors. For Cohort 2, mRNA data were compared using one-factor analysis of variance. In all cases, data that were not normally distributed were log transformed (base e) to achieve data normality. Post-ANOVA comparisons among means were made using the Holm-Sidak method. A $P$ value of $<0.05$ was considered statistically significant and all data are presented as mean $\underline{\text { S.E.M. }}$.

\section{Results}

Hippocampal gene expression during gestation and the early postnatal period in control animals

Total brain and hippocampal weights increased with advancing gestation (Fig. 1A and B). Levels of MR mRNA in saline controls were relatively constant throughout gestation and any apparent differences were not statistically significant (Fig. 2A). Levels of GR, however, increased between 75 and 109 dG, decreased dramatically between 116 and $121 \mathrm{dG}$, remained low for the rest of gestation and the immediate post-partum period but rose again at 12 weeks of postnatal age (Fig. 2B). We found that $11 \beta$ HSD1 mRNA followed a profile similar to that of GR (Fig. 2C); rising between 75 and $109 \mathrm{dG}$, and then declining to lower values between 116 and 132 dG. 11ßHSD2 mRNA was undetectable with the methods used in this study.

Effects of maternal betamethasone injections on hippocampal gene expression during pregnancy and early postnatal life

The fetuses of mothers treated with betamethasone had significantly reduced brain weight at 109, 116, and $121 \mathrm{dG}$ as well as at 6 weeks of age (Fig. 1A). Differences in hippocampal weights were not statistically significant (Fig. 1B). Fetal or maternal betamethasone injections (single or repeated) significantly reduced brain weight at $3 \cdot 5$ years of age (Moss et al. 2005). The hippocampal samples were not weighed at postmortem in adult offspring.

Betamethasone had transient effects on the levels of MR and GR mRNA in the fetal hippocampus (Fig. 2A and B); MR was decreased at $109 \mathrm{dG}$ but increased at $116 \mathrm{dG}$ and GR was increased at $116 \mathrm{dG}$. The ratio of MR to GR was not significantly different between control and betamethasone groups either in the fetuses or in lambs at 6 and 12 weeks of postnatal age (data not shown). The levels of $11 \beta$ HSD1 mRNA in the fetuses of mothers treated with betamethasone followed a profile similar to the fetuses of control ewes, with the exception that $11 \beta$ HSD1 mRNA levels at 12 -week postnatal age were elevated in exposed fetuses compared with
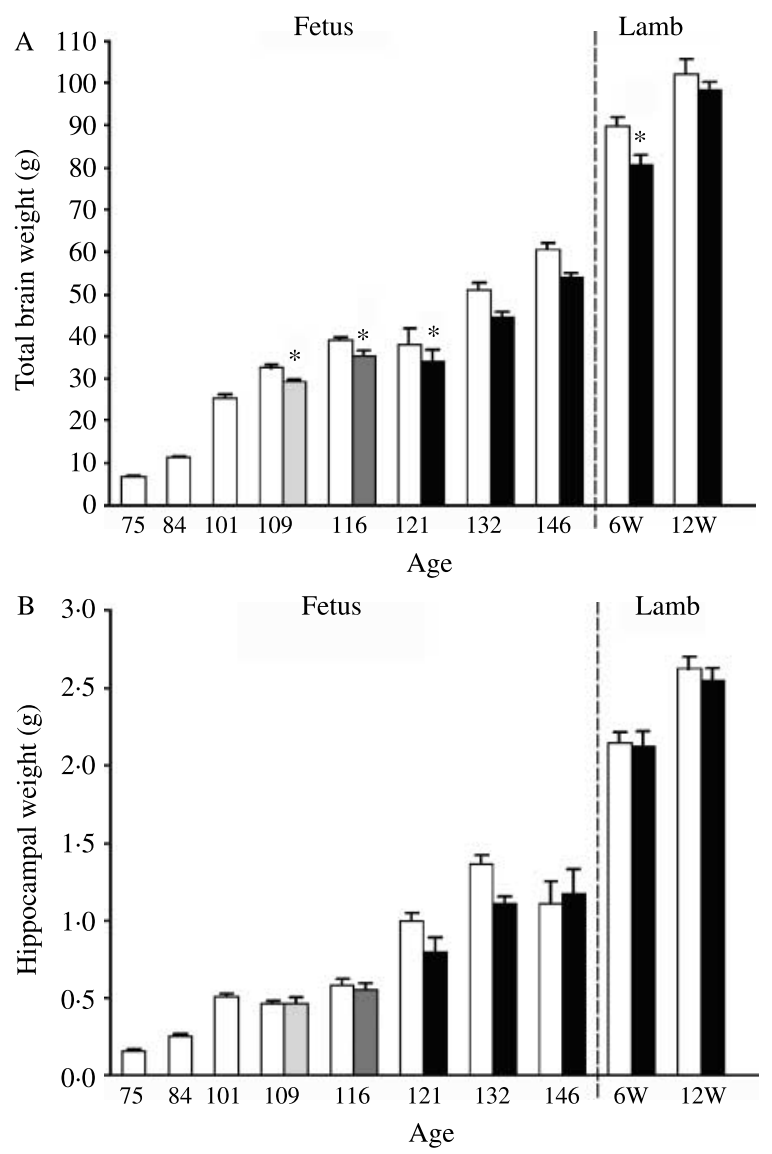

Figure 1 Histograms representing (A) total brain weight and (B) hippocampal weight in fetal and early postnatal lambs exposed to prenatal maternal betamethasone injections. Saline controls $\square$; after one maternal betamethasone injection $\square$; after two maternal betamethasone injections $\square$; and after three maternal betamethasone injections . Values are presented as mean \pm S.E.M. Asterisks represent $P<0.05$ versus saline controls. Total brain and hippocampal weights increased with advancing gestation all animals $(P<0 \cdot 05)$. Betamethasone exposure significantly decreased brain weight at 109, 116 and $121 \mathrm{dG}$ and at 6-week postnatal age, but had no effect on hippocampal weight.

controls (Fig. 2C). 11ßHSD2 remained undetectable in betamethasone-exposed fetuses.

\section{Effects of maternal betamethasone injections on hippocampal gene expression in adulthood}

The levels of MR mRNA in the hippocampus of adult offspring were significantly elevated in animals whose mothers had received one or four injections of betamethasone during pregnancy (Fig. 3A). GR mRNA levels were unchanged (Fig. 3B) and hence $M R$ to GR ratios were significantly increased after in utero betamethasone exposure (MS: 0.99 $\pm 0 \cdot 01$; M1:1.92 \pm 0.21; M4: $1 \cdot 67 \pm 0 \cdot 08 ; P<0 \cdot 05)$. The levels of $11 \beta \mathrm{HSD} 1$ mRNA in betamethasone-exposed offspring were not different from controls (Fig. 3C). The levels of 11ßHSD2, however, were 

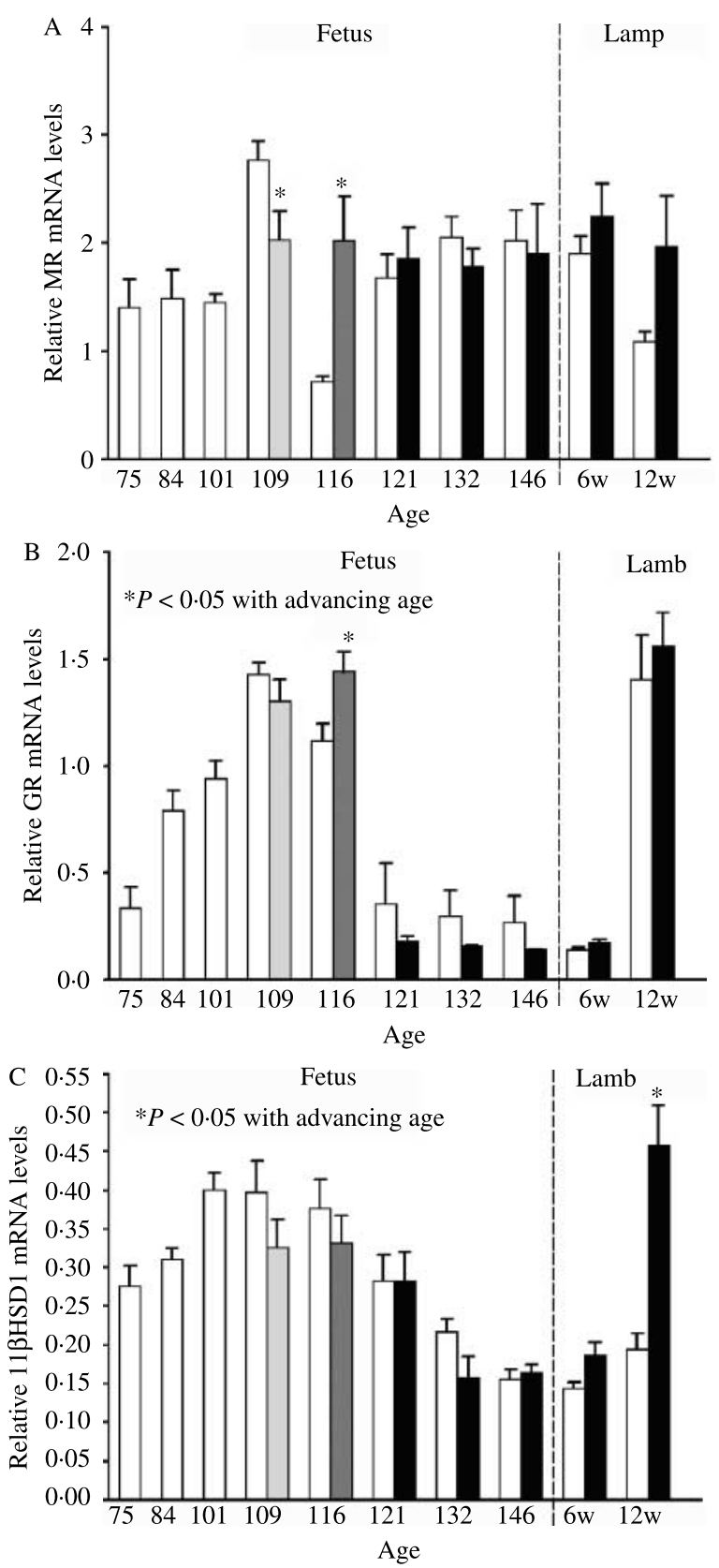

Figure 2 Histograms representing relative (A) $M R$, (B) $G R$, and (C) $11 \beta \mathrm{HSD} 1 \mathrm{mRNA}$ in the hippocampus of fetal and early postnatal lambs exposed to prenatal maternal betamethasone injections. Saline controls $\square$; after one maternal betamethasone injection $\square$; after two maternal betamethasone injections $\square$; and after three maternal betamethasone injections $\mathbf{m}$. Values are presented as mean \pm s.E.M. Asterisks represent $P<0 \cdot 05$ versus saline controls. Relative GR and $11 \beta \mathrm{HSD} 1 \mathrm{mRNA}$ levels changed significantly with advancing gestation in all animals $(P<0 \cdot 05)$, demonstrating peak levels at midgestation, around the time of the period of rapid brain growth in the fetal sheep. Betamethasone exposure had no effect on these levels.
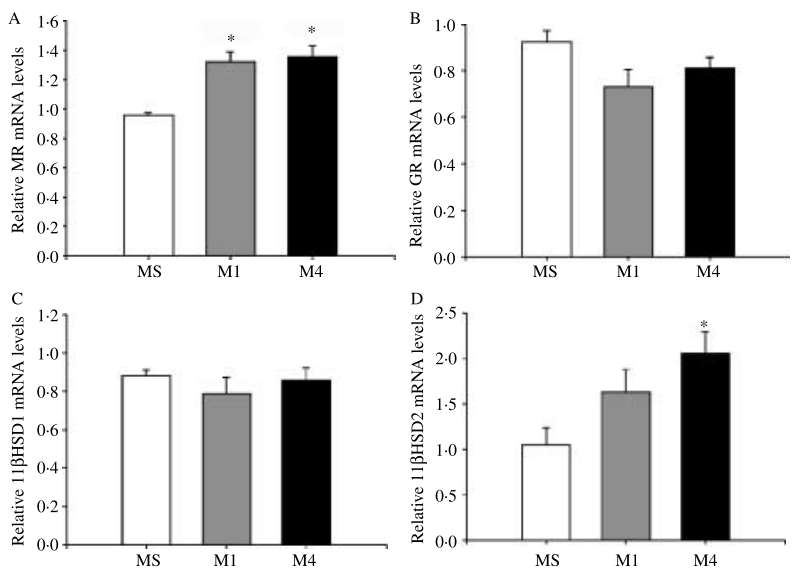

Figure 3 Histograms representing relative (A) $M R$, (B) $G R$, (C) $11 \beta \mathrm{HSD} 1 \mathrm{mRNA}$, and (D) $11 \beta \mathrm{HSD} 2 \mathrm{mRNA}$ in the hippocampus of adult offspring (at 3.5 years of age) exposed to maternal betamethasone injections. Maternal saline controls (MS) $\square$; single maternal betamethasone injection (M1) $\square$; four maternal betamethasone injections (M4) $\mathbf{m}$. Values are presented as mean \pm S.E.M. Asterisks represent $P<0.05$ versus saline controls. Prenatal exposure to maternal BETA significantly increased adult hippocampal levels of MR and 11ßHSD2 mRNA.

significantly increased in those animals whose mothers had received four weekly injections (Fig. 3D, M4). A single maternal injection of betamethasone resulted in an intermediate level of $11 \beta \mathrm{HSD} 2 \mathrm{mRNA}$ in the offspring of these pregnancies (Fig. 3D, M1). These trends were discernable in both male and female animals (Table 3 ). The effects of direct fetal injections of betamethasone were variable; there was a decrease in $\mathrm{MR}$ mRNA after a single fetal injection at d104 $(P<0 \cdot 05)$ and a decrease in 11ßHSD1 after one and four fetal betamethasone injections $(P<0 \cdot 05)$, but no other effects were observed (data not shown).

\section{Discussion}

Hippocampal gene expression ontogeny and fetal HPA development in control animals

Little is known about the relationship between hippocampal gene expression ontogeny and control of fetal HPA activity during gestation, but changes in hippocampal function are likely to be implicated in the late-gestational increases in fetal HPA activity, which are observed across many species, and could potentially mediate short- or long-term alterations of HPA function which result from physiological perturbations that the fetus is subjected to in utero.

In this study, we have presented novel data implicating the glucocorticoid metabolizing enzyme $11 \beta \mathrm{HSD} 1$ in the hippocampal regulation of HPA axis function in the ovine fetus. Control fetuses late in gestation demonstrated a dramatic decrease in the levels of mRNA encoding GR and $11 \beta \mathrm{HSD} 1$, suggestive of a potential role for these genes in 
Table 3 Mean relative mRNA levels of glucocorticoid receptor (GR), mineralocorticoid receptor (MR), $11 \beta$-hydroxysteroid dehydrogenase $(11 \beta \mathrm{HSD}) 1$, and $11 \beta \mathrm{HSD} 2$ in adult sheep (Cohort 2$)$ grouped according to sex. Data are presented as mean \pm S.E.M.

Maternal treatments

\begin{tabular}{|c|c|c|c|c|c|c|}
\hline & \multicolumn{2}{|l|}{ MS } & \multicolumn{2}{|l|}{ M1 } & \multicolumn{2}{|l|}{ M4 } \\
\hline & $\delta^{\pi}(n=3)$ & $\stackrel{(n=2)}{(n)}$ & $\delta^{\star}(n=2)$ & $q(n=3)$ & $\delta^{\star}(n=2)$ & $q(n=3)$ \\
\hline GR & $0 \cdot 78 \pm 0 \cdot 14$ & $0.93 \pm 0.03$ & $0 \cdot 57 \pm 0 \cdot 04$ & $0 \cdot 87 \pm 0 \cdot 07$ & $0 \cdot 73 \pm 0 \cdot 04$ & $0 \cdot 87 \pm 0 \cdot 05$ \\
\hline MR & $0.97 \pm 0.03$ & $1 \cdot 02 \pm 0 \cdot 03$ & $1 \cdot 26 \pm 0 \cdot 06$ & $1 \cdot 38 \pm 0 \cdot 13$ & $1 \cdot 18 \pm 0 \cdot 07$ & $1 \cdot 47 \pm 0.07$ \\
\hline $11 \beta \mathrm{HSD} 1$ & $0 \cdot 9 \pm 0 \cdot 05$ & $0 \cdot 85 \pm 0 \cdot 05$ & $0 \cdot 78 \pm 0 \cdot 20$ & $0 \cdot 80 \pm 0 \cdot 05$ & $0 \cdot 94 \pm 0 \cdot 05$ & $0 \cdot 84 \pm 0 \cdot 09$ \\
\hline $11 \beta \mathrm{HSD} 2$ & $1 \cdot 11 \pm 0 \cdot 25$ & $0 \cdot 87 \pm 0 \cdot 03$ & $1 \cdot 62 \pm 0 \cdot 17$ & $1 \cdot 64 \pm 0.59$ & $1 \cdot 62 \pm 0.41$ & $2 \cdot 35 \pm 0 \cdot 14$ \\
\hline
\end{tabular}

MS, maternal saline; M1, maternal one dose; M4, maternal four dose groups.

lessening the negative feedback influence of circulating or locally produced cortisol on the hippocampal regulation of HPA activity. Our data, together with previous reports (Andrews \& Matthews 2000, Keller-Wood et al. 2006), suggest that a reduction in late gestational hippocampal GR could facilitate a rise in fetal adrenocorticotropin (ACTH) and cortisol levels through a release of the hippocampal restraint on HPA activity. Here we further suggest that fetal hippocampal 11ßHSD1 may regulate glucocorticoid accessibility to hippocampal GR (and MR) during fetal life by converting local inactive cortisone to bio-active cortisol. Moreover, since peak levels of hippocampal GR and $11 \beta \mathrm{HSD} 1$ occur during the period of maximum brain growth in the ovine fetus (Dobbing \& Sands 1979), it could be that both GR and $11 \beta \mathrm{HSD} 1$ play a role in glucocorticoidrelated neuronal development and differentiation. The fact that we were unable to detect mRNA levels of $11 \beta \mathrm{HSD} 2$ suggests that the clearance of endogenous glucocorticoids in the fetal hippocampus by $11 \beta \mathrm{HSD} 2$ may not be a mechanism that contributes to the regulation of the HPA axis in fetal sheep. This observation is at odds with published data on fetal $11 \beta$ HSD2 development in the fetal rat (Diaz et al. 1998) and strengthens the argument that there are clear species differences in HPA maturation.

Most published data suggest a role for the hippocampus in the negative regulation of HPA axis activity, although there is some evidence that this regulation may be more complex than previously suggested (Tuvnes et al. 2003). Nevertheless, our data suggest that in ovine fetus, hippocampal GR, and 11ßHSD1 may act in concert with hypothalamic and pituitary maturation late in gestation to facilitate both the well-established decrease in the negative feedback regulation of HPA axis activity, and a rise in fetal ACTH and cortisol levels.

Effects of maternal betamethasone injections on hippocampal gene expression during pregnancy and early postnatal life

Since fetus may experience prolonged exposure to both endogenous and exogenous glucocorticoids in utero, and given our previous observations that exposure to glucocorticoids increases fetal HPA axis activity at the term (Sloboda et al. 2000), we aimed to determine whether this would alter the expression of regulatory genes in the fetal hippocampus. We demonstrated transient changes in hippocampal MR and GR mRNA at 109 and $116 \mathrm{dG}$ after betamethasone exposure. Further work is, however, required to establish whether these observations reflect underlying trends of sufficient magnitude to drive outcomes such as enhanced activity of the fetal HPA axis in the term. We have previously shown that fetal betamethasone exposure did not alter hypothalamic corticotropin-releasing hormone, arginine vasopressin, GR, or pituitary proopiomelanocortin mRNA levels (Sloboda et al. 2000). Based on the data that we report here, if changes in hippocampal gene expression are not responsible for betamethasone-induced changes in HPA activity (Sloboda et al. 2000), it is possible that changes could be driven by alterations at lower levels of the axis such as the adrenal gland.

The increase in 11ßHSD1 mRNA levels in 12-week-old offspring is not sustained to adulthood but suggests the potential for locally synthesized glucocorticoids in the hippocampus to influence HPA function.

Effects of maternal betamethasone injections on hippocampal gene expression in adulthood

In contrast to our observations in the fetus, we have demonstrated a significant upregulation of hippocampal MR mRNA in adult offspring of mothers injected with betamethasone. The fact that this increase was observed in adulthood but not in fetal or early postnatal life suggests that this effect may be an indirect consequence of maternal betamethasone administration, rather than a direct effect. We have shown previously that basal ACTH levels are elevated in the face of reduced basal cortisol in these same offspring (Sloboda et al. 2007). Our observed increases in hippocampal MR would be expected to attenuate circulating levels of ACTH and cortisol. We therefore suggest that the upregulation of hippocampal MR mRNA in the current study may be a consequence of reduced levels of circulating cortisol levels (Sloboda et al. 2007) in these same offspring. This is possible since autologous regulation of $\mathrm{MR}$ gene expression has been demonstrated previously in the hippocampus of rats (Holmes et al. 1995, Kalman \& Spencer 2002). Our observations are most consistent with those reported in the guinea pig (Dean et al. 2001, McCabe et al. 2001, Banjanin 
et al. 2004), where prenatal dexamethasone administration resulted in reduced basal and stimulated HPA axis function in male offspring and was associated with elevated hippocampal MR (but not GR) mRNA in the dentate gyrus (DG; Liu et al. 2001).

Significant changes in postnatal hippocampal MR/GR balance consistent with our observations reported here may compromise homeostasis and lead to further HPA dysregulation (De Kloet \& Derijk 2004). An imbalance in the ratio of MR to GR appears to be influenced by the availability of corticosteroids and co-regulators, and by access to receptors (De Kloet \& Derijk 2004), which in the present study could be regulated by changes in the $11 \beta \mathrm{HSD}$ enzymes. Although we did not measure enzymatic activity, it is possible that our observed increase in hippocampal 11ßHSD2 mRNA in adult sheep resulted in an elevation in $11 \beta \mathrm{HSD} 2$ activity and a reduction in the cellular availability of endogenous glucocorticoids. A reduction in intracellular glucocorticoid levels in the hippocampus would have downstream effects on central hippocampal negative feedback, through alterations in the accessibility to corticosteroid receptors. It has been shown previously that $11 \beta \mathrm{HSD} 1$ knockout mice had increased HPA activity, attributable to either increased drive and/or attenuated negative feedback (Harris et al. 2001). It is unknown whether 11ßHSD2 overexpression in the hippocampus would have the same effects. It is tempting to speculate that an increase in $11 \beta \mathrm{HSD} 2$ would decrease intracellular levels of cortisol in the hippocampus and contribute to the upregulation of MR; but further studies are required to substantiate this.

In order to investigate the effects of synthetic glucocorticoids in the fetal compartment, we have also examined the effects of administering glucocorticoids to the fetus directly, as although synthetic glucocorticoids themselves are not metabolized in the placenta, we have shown that betamethasone may affect placental function (Braun et al. 2007). We found that a single direct fetal betamethasone injection decreased hippocampal MR, but had no net effect on MR to GR ratios, and that repeated injections had no further effect on MR or GR. These data are therefore consistent with our previous reports that HPA axis function is not altered after fetal betamethasone administration (Sloboda et al. 2002, 2007).

Although this study did not involve an analysis of hippocampal sub-regions, our findings do not contradict other studies that have focused on gene expression in specific sub-regions of the brain (Dean et al. 2001, Romeo et al. 2008). We recognize the existence of sex-specific effects of betamethasone on hippocampal gene expression; although the numbers of adult animals available in the present study did not allow us to assess the effect of sex, our observed effects were discernable in both male and female animals.

In summary our measurements have shown 1) that there are changes in hippocampal GR and $11 \beta \mathrm{HSD} 1$, which are consistent with altered ontogenetic feedback, allowing increased fetal HPA axis activity in the term; 2) that although exogenous glucocorticoids have acute effects on fetal hippocampal MR and GR, these effects are not sustained throughout fetal life; and 3) that the administration of synthetic glucocorticoids to pregnant sheep resulted in significant increases in MR and $11 \beta \mathrm{HSD} 2$ gene expression in adult animals, reflecting the potential for longer term alterations in HPA function. These observations suggest a possible role for locally produced glucocorticoids within the hippocampus in facilitating fetal HPA axis activity and possibly brain development. Furthermore, fetal exposure to synthetic glucocorticoids has effects on the hippocampal expression of corticosteroid receptors and metabolizing enzymes - effects that appear to be modified over the lifespan of the offspring.

\section{Acknowledgements}

The authors thank Dr Ilias Nitsos, Adrian Jonker, Amanda Johnston, Alana Mason, and Samantha Durling, who made contributions to tissue collection. This study was supported by the National Health and Medical Research Council of Australia (project grants 980578 and 139026 and Career Development Award 303261), the Women and Infants Research Foundation of Western Australia, the Western Australian Raine Medical Research Foundation (grant no. 74301003), the Child Health Research Foundation of WA Inc., and the Canadian Institutes of Health Research (CIHR) Group in Fetal and Neonatal Health and Development. The authors declare that there is no conflict of interest that would prejudice the impartiality of this scientific work.

\section{References}

Andrews MH \& Matthews SG 2000 Regulation of glucocorticoid receptor mRNA and heat shock protein 70mRNA in the developing sheep brain. Brain Research 878 174-182.

Banjanin S, Kapoor A \& Matthews SG 2004 Prenatal glucocorticoid exposure alters hypothalamic-pituitary-adrenal function and blood pressure in mature male guinea pigs. Journal of Physiology 558 305-318.

Braun T, Li S, Moss TJ, Newnham J, Challis JRG, Gluckman P \& Sloboda DM 2007 Maternal betamethasone administration reduces binucleate cell number and plancental lactogen in sheep. Journal of Endocrinology 194 337-347.

Dean F, Yu C, Lingas RI \& Matthews SG 2001 Prenatal glucocorticoid modifies hypothalamo-pituitary-adrenal regulation in prepubertal guinea pigs. Neuroendocrinology 73 194-202.

Diaz R, Brown RW \& Seckl JR 1998 Distinct ontogeny of glucocorticoid and mineralocorticoid receptor and 11beta-hydroxysteroid dehydrogenase types I and II mRNAs in the fetal rat brain suggest a complex control of glucocorticoid actions. Journal of Neuroscience 18 2570-2580.

Dobbing J \& Sands J 1979 Comparative aspects of the brain growth spurt. Early Human Development 3 79-83.

Dodic M, Hantzis V, Duncan J, Rees S, Koukoulas I, Johnson K, Wintour EM \& Moritz K 2002 Programming effects of short prenatal exposure to cortisol. FASEB Journal 16 1017-1026.

Harris HJ, Kotelevtsev Y, Mullins JJ, Seckl JR \& Holmes MC 2001 Intracellular regeneration of glucocorticoids by 11 beta-hydroxysteroid dehydrogenase (11beta-HSD)-1 plays a key role in regulation of the hypothalamic-pituitary-adrenal axis: analysis of 11beta-HSD-1-deficient mice. Endocrinology 142 114-120. 
Holmes MC, Yau JLW, French KL \& Seckl JR 1995 The effect of adrenalectomy on 5-hydroxytryptamine and corticosteroid receptor subtype messenger RNA expression in rat hippocampus. Neuroscience $64327-337$.

Huang WL, Beazley LD, Quinlivan JA, Evans S, Newnham J \& Dunlop SA 1999 Effect of corticosteroids on brain growth in fetal sheep. Obstetrics and Gynecology 94 213-218.

Jobe AH, Wada N, Berry LM, Ikegami M \& Ervin MG 1998 Single and repetitive maternal glucocorticoid exposures reduce fetal growth in sheep. American Journal of Obstetrics and Gynecology 178 880-885.

Kalman BA \& Spencer RL 2002 Rapid corticosteroid-dependent regulation of mineralocorticoid receptor protein expression in rat brain. Endocrinology 143 4184-4195.

Keller-Wood M, Powers MJ, Gersting JA, Ali N \& Wood CE 2006 Genomic analysis of neuroendocrine development of fetal brain-pituitary-adrenal axis in late gestation. Physiological Genomics 24 218-224.

De Kloet R \& Derijk R 2004 Signaling pathways in brain involved in predisposition and pathogenesis of stress-related disease: genetic and kinetic factors affecting the MR/GR balance. Annals of the New York Academy of Sciences 1032 14-34.

Levitt NS, Lindsay RS, Holmes MC \& Seckl JR 1996 Dexamethasone in the last week of pregnancy attenuates hippocampal glucocorticoid receptor gene expression and elevates blood pressure in the adult offspring in the rat. Neuroendocrinology 64 412-419.

Liggins GC 1994 The role of cortisol in preparing the fetus for birth. Reproduction, Fertility, and Development 6 141-150.

Liu L, Li A \& Matthews SG 2001 Maternal glucocorticoid treatment programs HPA regulation in adult offspring: sex-specific effects. American Journal of Physiology. Endocrinology and Metabolism 280 E729-E739.

Matthews SG \& Challis JRG 1996 Regulation of the hypothalamo-pituitaryadrenocortical axis in fetal sheep. Trends in Endocrinology and Metabolism 7 239-246.

McCabe L, Marash D, Li A \& Matthews SG 2001 Repeated antenatal glucocorticoid treatment decreases hypothalamic corticotropin releasing hormone mRNA but not corticosteroid receptor mRNA expression in the fetal guina-pig brain. Journal of Neuroendocrinology 13 425-431.

Meaney MJ \& Aitken DH 1985 The effects of early postnatal handling on hippocampal glucocorticoid receptor concentrations: temporal parameters. Developmental Brain Research 22 301-304.

Meaney MJ, Aitken DH, Viau V, Sharma S \& Sarrieau A 1989 Neonatal handling alters adrenocortical negative feedback sensitivity and hippocampal type II glucocorticoid receptor binding in the rat. Neuroendocrinology 50 597-604.

Moss TJ, Sloboda DM, Gurrin LC, Harding R, Challis JRG \& Newnham J 2001 Programming effects in sheep of prenatal growth restriction and glucocorticoid exposure. American Journal of Physiology 281 R960-R970.
Moss TJM, Doherty D, Nitsos I, Sloboda DM, Harding R \& Newnham JP 2005 Effects into adulthood of single or repeated antenatal corticosteroids in sheep. American Journal of Obstetrics and Gynecology 192 146-152.

Nathanielsz PW, Buster JE, Jenkin G, Jorgensen G \& Thorburn GD 1988 Induction of premature delivery in sheep following infusion of cortisol to the fetus: the effect of maternal progestagen treatment on the C21-steroid$17 \alpha$ hydroxylase, C17, 20 lyase and aromatase pathways. Journal of Developmental Physiology 10 257-270.

Newnham JP, Evans SF, Godfrey M, Huang W, Ikegami M \& Jobe A 1999 Maternal, but not fetal, administration of corticosteroids restricts fetal growth. Journal of Maternal-Fetal Medicine 8 81-87.

Quinlivan JA, Dunlop SA, Newnham J, Evans SF \& Beazley LD 1999 Repeated, but not single, maternal administration of corticosteroids delays myelination in the brain of fetal sheep. Prenatal and Neonatal Medicine 4 47-55.

Romeo RD, Ali FS, Karatsoreos IN, Bellani R, Chhua N, Vernov M \& McEwen BS 2008 Glucocorticoid receptor mRNA expression in the hippocampal formation of male rats before and after pubertal development in response to acute or repeated stress. Neuroendocrinology (In press).

Sloboda DM, Newnham J \& Challis JRG 2000 Effects of repeated maternal betamethasone administration on growth and hypothalamic-pituitaryadrenal function of the ovine fetus at term. Journal of Endocrinology 165 79-91.

Sloboda DM, Moss TJ, Gurrin LC, Newnham J \& Challis JRG 2002 The effect of prenatal betamethasone administration on postnatal ovine hypothalamic-pituitary-adrenal function. Journal of Endocrinology 172 71-81.

Sloboda DM, Moss TJM, Li S, Doherty DA, Nitsos I, Challis JRG \& Newnham JP 2005 Hepatic glucose regulation and metabolism in adult sheep: effects of prenatal betamethasone. American Journal of Physiology. Endocrinology and Metabolism 289 E721-E728.

Sloboda DM, Moss TJM, Li S, Doherty D, Nitsos I, Challis JRG \& Newnham JP 2007 Prenatal betamethasone exposure results in pituitary-adrenal hyporesponsiveness in adult sheep. American Journal of Physiology. Endocrinology and Metabolism 292 E61-E70.

Tuvnes FA, Steffenach H-A, Murison R, Moser M-B \& Moser EI 2003 Selective hippocampal lesions do not increase adrenocortical activity. Journal of Neuroscience 23 4345-4354.

\section{Received in final form 6 February 2008 \\ Accepted 4 March 2008 \\ Made available online as an Accepted Preprint 4 March 2008}

